\title{
Prevalence of Gram-negative and Gram-positive Bacteria and Antibiotic Resistance Rates at a Military Hospital in Riyadh Region
}

\author{
Nehad Jaser Ahmed ${ }^{1,2, *}$, Mohammad Abdalla ${ }^{3}$, Hadeel Alahmadi ${ }^{3}$, Abdul Haseeb ${ }^{4}$, Amer Hayat Khan $^{2}$ \\ 'Department of Clinical Pharmacy, College of Pharmacy, Prince Sattam Bin Abdulaziz University, Al-Kharj, SAUDI ARABIA. \\ 2Discipline of Clinical Pharmacy, School of Pharmaceutical Sciences, Universiti Sains Malaysia, George Town, Penang, MALAYSIA. \\ ${ }^{3}$ Microbiology Section, Department of Pathology, Alkharj Military Industrial Corporation Hospital, Alkharj, SAUDI ARABIA. \\ ${ }^{4}$ Clinical Pharmacy Department, College of Pharmacy, Umm AIQura University, Mecca, SAUDI ARABIA.
}

\begin{abstract}
Aim: This study aimed to investigate the prevalence of gram negative and gram positive bacteria in addition to the investigation of antibiotic resistance rates in 2021 at a military hospital in Riyadh Region. Materials and Methods: This observational study included the retrospective review of bacterial isolates from $1^{\text {st }}$ of January 2021 to $30^{\text {th }}$ of June 2021. Results: Most of the infections were caused by gram negative bacteria $(64.52 \%)$. The most common gram negative bacteria were Escherichia coli $(43.63 \%)$ followed by Pseudomonas aeruginosa (20.52\%). The most common gram positive bacteria were Staphylococcus aureus isolates (71.74\%). The study also showed that Acinetobacter baumannii was a pandrug-resistant bacterium and Enterobacter cloacae, Proteus mirabilis, Morganella morganii, and Enterococcus faecalis bacteria were multidrug resistant. Conclusion: There was a high resistance for some bacteria to numerous antibiotics. Antibiotic susceptibility testing is an essential guide
\end{abstract}

for physicians to help them in the selection of the suitable antibiotic for bacterial infections.

Key words: Antibiotic resistance, Antimicrobial resistance, Gram negative bacteria, Gram positive bacteria, Multidrug-resistant bacteria, Prevalence.

Correspondence

Mr. Nehad Jaser Ahmed, ${ }^{1,2}$

${ }^{1}$ Clinical Pharmacy Department, College of Pharmacy, Prince Sattam Bin Abdulaziz University, Al-Kharj, SAUDI ARABIA.

2Discipline of Clinical Pharmacy, School of Pharmaceutical Sciences, Universiti Sains Malaysia, George Town, Penang, MALAYSIA.

Email id: pharmdnehadjaser@yahoo.com

DOI: 10.5530/jyp.2021.13.95

\section{INTRODUCTION}

Antibiotics can save lives, but when antibiotics are used, they can cause adverse effects and can lead to antibiotic resistance. ${ }^{1}$ In Saudi Arabia, the rate of antibiotics misuse is complicated and high mainly because before several years, antibiotics were available to everyone as over the counter medications by pharmacies. ${ }^{2}$ Alrasheedy et al. sated that nationwide ban on the sale of antibiotics without a prescription was implemented currently by Saudi Ministry of Health; nevertheless, antibiotics dispensing without a written prescription is still frequent. ${ }^{2}$

The misuse of antibiotics is known to increase the development of bacterial resistance to antibiotics. ${ }^{3,4}$ Yitayeh et al. stated that the effectiveness of the available antibiotics is decreased and bacterial resistance to different antibiotics is increased globally. ${ }^{5}$ In the United States, it is estimated that about two million patients develop a bacterial infection that is resistant to antibiotics annually and that more than 23 thousands deaths are related to these infections. ${ }^{6}$ Antibiotic resistance results in an increase in hospital stay, mortality, morbidity, and healthcare costs in addition to limiting the number of effective antimicrobial agents. ${ }^{7-9}$

Escherichia coli, Klebsiella pneumoniae, Pseudomonas aeruginosa, Streptococcus pneumoniae, Staphylococcus aureus, and Salmonella spp. are frequently isolated microbes from infections in the community and clinical settings; ${ }^{10}$ they are the most serious antibiotic resistant microorganisms recently. ${ }^{11}$

To to guide antimicrobial therapy and predict the efficacy of the antimicrobial agents, antimicrobial susceptibility testing results should be used. Therefore, this study aimed to investigate the prevalence of gram negative and gram positive bacteria in addition to the investigation of antibiotic resistance rates in 2021 at a military hospital in Riyadh Region.

\section{MATERIALS AND METHODS}

This observational study included the retrospective review of bacterial isolates from $1^{\text {st }}$ of January 2021 to $30^{\text {th }}$ of June 2021 . This study was conducted at military hospital in Riyadh Region that is tertiary hospitals provide medical services in different sections obstetrics, paediatrics, gynecology, general surgery, ophthalmology, neurology, dental medicine, dialysis unit, psychiatry, and otolaryngology. This observational study was approved by the ethical committee in the military hospital with a $\log$ number of 4101728 . The results of the pathogenic bacteria recovered from various microbiological samples (such as wound, blood, and urine) were included in the study and the cultures before or after the study period were excluded.

The data were collected by pathology department/microbiology section in the military hospital. After data collection, antimicrobial susceptibility report was prepared for the bacterial isolates. The data included the number and percentages of gram negative and gram positive bacteria and the resistance rate of bacteria to different antimicrobials. The descriptive data were shown as numbers and percentages.

\section{RESULTS}

Most of the infections were caused by gram negative bacteria (64.52\%). The number of gram negative and gram-positive bacteria is shown in Table 1. Escherichia coli were the most common bacteria (43.63\%) followed by Pseudomonas aeruginosa (20.52\%) and Klebsiella pneumonia 
(16.73\%). Percentages of gram-negative and isolates were summarized in Tables 2, 3.

Table 4 shows the susceptibility rate of gram-negative bacteria to different antibiotics. The resistance of Escherichia coli was more than $50 \%$ only to ampicillin (susceptibility rate $=34 \%$ ). Similarly, the resistance rate of Klebsiella pneumonia was high only to ampicillin (susceptibility rate $=1 \%$ ) and Nitrofurantoin (susceptibility rate $=37 \%$ ). The resistance

Table 1: Number and percentage of gram positive and gram negative bacteria.

\begin{tabular}{ccc}
\hline Micro-organisms & $\begin{array}{c}\text { Number of bacteria } \\
\text { isolates }\end{array}$ & Percentage \\
\hline Gram Negative bacteria & 502 & 64.52 \\
Gram positive bacteria & 276 & 35.48 \\
Total & 778 & 100.00 \\
\hline
\end{tabular}

Table 2: Number and percentage of gram-negative bacterial isolates.

\begin{tabular}{ccc}
\hline Micro-organism & Number of bacteria & Percentage \\
\hline Escherichia coli & 219 & 43.63 \\
Pseudomonas aeruginosa & 103 & 20.52 \\
Klebsiella pneumoniae & 84 & 16.73 \\
Proteus mirabilis & 35 & 6.97 \\
Acinetobacter baumannii & 28 & 5.58 \\
Morganella morganii & 17 & 3.39 \\
Enterobacter cloacae & 16 & 3.18 \\
Total & 502 & 100.00 \\
\hline
\end{tabular}

Table 3: Number and percentage of gram-positive bacterial isolates.

\begin{tabular}{ccc}
\hline Micro-organism & Number of bacteria & Percentage \\
\hline Staphylococcus aureus & 198 & 71.74 \\
Staphylococcus epidermidis & 44 & 15.94 \\
Enterococcus faecalis & 34 & 12.32 \\
Total & 276 & 100.00 \\
\hline
\end{tabular}

of Enterobacter cloacae was high to several antibiotics particularly ampicillin (susceptibility rate $=0 \%$ ), co-amoxiclav (susceptibility rate $=0 \%$ ), cefazolin (susceptibility rate $=0 \%$ ) and cefoxitin (susceptibility rate $=0 \%$ ). The resistance of Proteus mirabilis was also high for several antibiotics mainly to ampicillin (susceptibility rate=29), nitrofurantoin (susceptibility rate $=0 \%$ ), and ceftriaxone (susceptibility rate $=37 \%$ ).

Morganella morganii was highly resistant to ampicillin, ampicillin/ sulbactam, amoxicillin/clavulanate, cefuroxime, norfloxacin and nitrofurantoin. The resistance of Morganella morganii to all of these antibiotics was $100 \%$. The resistance of Pseudomonas aeruginosa was low to all of the tested antibiotics. The resistance of Acinetobacter baumannii was high (more than 50\%) for all of the tested antibiotics.

Table 5 shows the susceptibility rate of gram-positive bacteria to different antibiotics. Staphylococcus aureus was highly resistant to penicillin (susceptibility rate $=2 \%$ ) and ampicillin (susceptibility rate=2\%). Enterococcus faecalis was highly resistant to erythromycin (susceptibility rate $=5 \%$ ), tetracycline (susceptibility rate=24\%) and rifampin (susceptibility rate=50\%). Staphylococcus epidermidis was highly resistant to penicillin (susceptibility rate $=5 \%$ ), ampicillin (susceptibility rate $=5 \%$ ), oxacillin (susceptibility rate $=23 \%$ ), azithromycin (susceptibility rate $=29 \%$ ) and erythromycin (susceptibility rate $=26 \%$ ).

\section{DISCUSSION}

Most of the infections were caused by gram negative bacteria. The most common gram-negative bacteria were Escherichia coli isolates followed by Pseudomonas aeruginosa and Klebsiella pneumonia isolates. Staphylococcus aureus and Staphylococcus epidermidis were the most common gram-positive bacteria. A previous study showed that some bacteria such as Klebsiella pneumoniae, Enterococcus faecium, Acinetobacter baumannii, Staphylococcus aureus, Enterobacter, and Pseudomonas aeruginosa, that is known as ESKAPE pathogens, cause nearly half the infections that were caused by bacteria in a Public Hospital in Alkharj. ${ }^{12}$ Ahmed stated that among a military hospital in Riyadh Region, about $75.77 \%$ of infections were caused by gram negative bacteria and that the most common microorganisms were Escherichia coli, Pseudomonas aeruginosa, Staphylococcus aureus and Klebsiella pneumonia. ${ }^{13}$

Table 4: The susceptibility rate of gram-negative bacteria to different antibiotics.

\begin{tabular}{|c|c|c|c|c|c|c|c|c|c|c|c|c|c|c|c|c|c|c|c|c|c|c|c|}
\hline Organism & 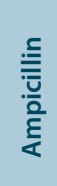 & $\begin{array}{l}\frac{0}{5} \\
\text { जิ } \\
\frac{\hat{o}}{\varepsilon} \\
\frac{c}{\alpha}\end{array}$ & 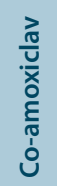 & 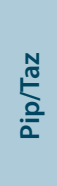 & 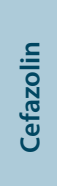 & 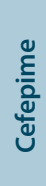 & 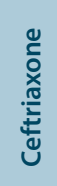 & 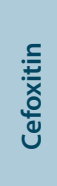 & 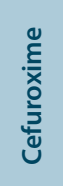 & 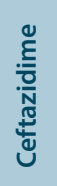 & 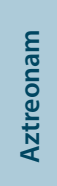 & 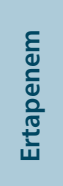 & 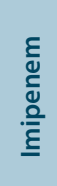 & 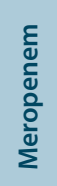 & 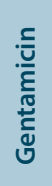 & 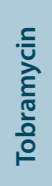 & 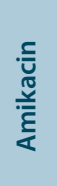 & 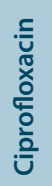 & 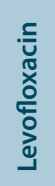 & 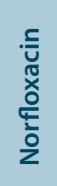 & $\begin{array}{l}\sum_{i=1}^{x} \\
\sum_{1}^{\infty}\end{array}$ & 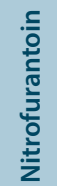 & $\frac{.5}{\overline{\underline{\underline{H}}}}$ \\
\hline Escherichia coli & 34 & 51 & 76 & 94 & 52 & 55 & 55 & 92 & 53 & 54 & 53 & 97 & 99 & 98 & 87 & 84 & 96 & 69 & 72 & 68 & 68 & 96 & NA \\
\hline $\begin{array}{c}\text { Klebsiella } \\
\text { pneumonia }\end{array}$ & 1 & 68 & 80 & 90 & 71 & 68 & 65 & 82 & 63 & 65 & 58 & 86 & 95 & 90 & 86 & 79 & 90 & 79 & 85 & 80 & 74 & 37 & NA \\
\hline $\begin{array}{c}\text { Enterobacter } \\
\text { cloacae }\end{array}$ & 0 & 12 & 0 & 81 & 0 & 69 & 50 & 0 & 12 & 56 & 56 & 62 & 75 & 88 & 75 & 81 & 88 & 69 & 75 & 50 & 88 & 17 & NA \\
\hline Proteus mirabilis & 29 & 43 & 63 & 91 & 55 & 63 & 37 & 80 & 49 & 49 & 57 & 86 & $\mathrm{NA}$ & 94 & 43 & 49 & 74 & 40 & 54 & 50 & 40 & 0 & NA \\
\hline $\begin{array}{c}\text { Morganella } \\
\text { morganii }\end{array}$ & 0 & 0 & 0 & 88 & NA & 76 & NA & 76 & 0 & 59 & 76 & 100 & 6 & 100 & 82 & 59 & 94 & 53 & 53 & 0 & 35 & 0 & NA \\
\hline $\begin{array}{c}\text { Pseudomonas } \\
\text { aeruginosa }\end{array}$ & NA & NA & NA & 72 & NA & 66 & NA & NA & NA & 67 & 60 & NA & 67 & 72 & 68 & 80 & 77 & 72 & 73 & 58 & NA & NA & 86 \\
\hline $\begin{array}{c}\text { Acinetobacter } \\
\text { baumannii }\end{array}$ & NA & 25 & NA & NA & NA & 21 & NA & NA & NA & 21 & NA & NA & 0 & 21 & 36 & 36 & 36 & 21 & 25 & NA & 21 & NA & NA \\
\hline
\end{tabular}

*TMP-SMX: Trimethoprim/Sulfamethoxazole, Amp-Sulb: Ampicillin/sulbactam, Co-amoxiclav: Amoxicillin/clavulanate, Pip/Taz: Piperacillin-tazobactam 
Table 5: The susceptibility rate of gram-positive bacteria to different antibiotics.

\begin{tabular}{|c|c|c|c|c|c|c|c|c|c|c|c|c|c|c|c|c|c|c|c|}
\hline$\#$ & 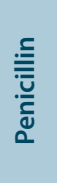 & 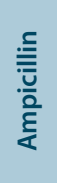 & 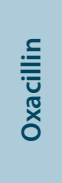 & 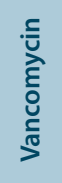 & $\begin{array}{l}\frac{.}{\frac{5}{c}} \\
\frac{\pi}{0} \\
\frac{0}{0} \\
\frac{0}{\omega}\end{array}$ & 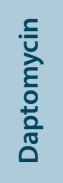 & 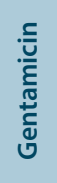 & 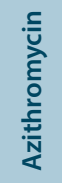 & 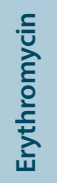 & 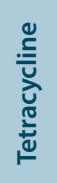 & 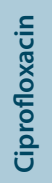 & 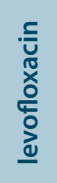 & 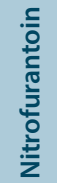 & 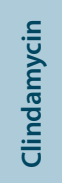 & $\begin{array}{l}\sum_{i=1}^{x} \\
\sum_{i}^{1} \\
\sum_{1}^{n}\end{array}$ & 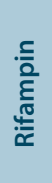 & ò & $\begin{array}{l}\text { 응 } \\
\stackrel{N}{\mathscr{N}} \\
\stackrel{\Xi}{\Xi}\end{array}$ & 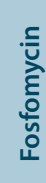 \\
\hline $\begin{array}{c}\text { Staphylococcus } \\
\text { aureus }\end{array}$ & 2 & 2 & 51 & 100 & NA & 95 & 85 & 65 & 65 & 85 & 65 & 68 & 100 & 82 & 94 & 96 & 96 & 96 & 95 \\
\hline Enterococcus faecalis & 94 & 88 & NA & 97 & 100 & 100 & NA & NA & 5 & 24 & 71 & 74 & 87 & NA & NA & 50 & NA & 100 & NA \\
\hline $\begin{array}{c}\text { Staphylococcus } \\
\text { epidermidis }\end{array}$ & 5 & 5 & 23 & 100 & NA & 98 & 57 & 29 & 26 & 77 & 57 & 59 & NA & 67 & 75 & 95 & 89 & 100 & 95 \\
\hline
\end{tabular}

*TMP-SMX: Trimethoprim/Sulfamethoxazole, Q-D: Quinupristin-dalfopristin

Ahmed and Khan reported that in a University Hospital in Al-Kharj, the most common bacteria were Escherichia coli (26.58\%), Klebsiella pneumonia (16.45\%) and that the percentages of Enterococcus faecalis, Pseudomonas aeruginosa and Staphylococcus aureus were 13.92\%, 12.65\% and $12.65 \%$ respectively. ${ }^{14}$ Moreover, Masoud et al. found that Najran Area, the most prevalent bacteria isolated were Escherichia coli (35.63\%), Klebsiella pneumoniae (18.08\%), and Staphylococcus aureus (14.89\%). ${ }^{15}$ Hamid et al. revealed that among pathogens causing infections in the Aseer regions, the main etiological agents were Escherichia coli isolates, Klebsiella pneumoniae isolates, Enterococcus spp. isolates and Staphylococcus aureus isolates. ${ }^{16}$ Aly and Balkhy reported that among clinical isolates from Gulf countries, the most prevalent bacteria were Escherichia coli (44\%),followed by Klebsiella pneumoniae (20\%), Pseudomonas aeruginosa (18.7\%), Methicillin-resistant Staphylococcus aureus (5.4\%), and Acinetobacter (5\%). ${ }^{17}$

The present study showed that the resistance rate of several pathogens was very high. Regarding gram negative bacteria, Enterobacter cloacae was very high to several antibiotics particularly ampicillin, co-amoxiclav, cefazolin and cefoxitin (susceptibility rate to all of these antibiotics $=0 \%$ ). Davin-Regli and Pagès stated that Enterobacter cloacae has an intrinsic resistance to ampicillin, amoxicillin, cefoxitin, and first generation cephalosporins, due to constitutive AmpC $\beta$-lactamase production and that it shows a high resistance to broad spectrum cephalosporins. ${ }^{18}$ Moreover, Malek et al. stated that multidrug resistant Enterobacter species are one of the common bacteria that cause hospital-acquired infections. ${ }^{19}$

The resistance of Proteus mirabilis was also high for several antibiotics mainly to ampicillin, nitrofurantoin, and ceftriaxone. A previous study in Taiwan revealed a reduced susceptibility of Proteus mirabilis to several broad spectrum antibiotics, such as ciprofloxacin and third generation cephalosporins, in the past decade. ${ }^{20}$ In contrast to that Tsai et al. informed that Proteus mirabilis is expected to be sensitive to broadspectrum penicillins (such as piperacillin and ticarcillin), ampicillin, first generation cephalosporins, second generation cephalosporins, third generation cephalosporins, aztreonam, and imipenem. ${ }^{21}$

In the present study, Morganella morganii was highly resistant to ampicillin, ampicillin/sulbactam, amoxicillin/clavulanate, cefuroxime, norfloxacin and nitrofurantoin. So, Enterobacter cloacae, Proteus mirabilis, and Morganella morganii bacteria were multidrug resistant; multidrug resistant was defined as acquired resistance to at least one antimicrobial in three or more different antimicrobial classes. ${ }^{22}$ Monnet and Richard reported that the Morganella morganii is generally resistant to amoxicillin-clavulanic acid combination, to cephalothin, and to ampicillin and that Morganella morganii bacteria are usually susceptible to other antibiotics active against gram negative bacilli. ${ }^{23}$ Liu et al. reported that infections with Morganella morganii are mostly worrisome epidemiologically due to the organism's inducible resistance to Betalactams. ${ }^{24}$

Furthermore, the resistance of Acinetobacter baumannii was high for all of the tested antibiotics. So, Acinetobacter baumannii was a pandrugresistant bacterium (pandrug-resistant was defined as resistant to all antimicrobials in all antimicrobial groups). But the susceptibility of Acinetobacter baumannii to colistin, which was considered as one of the last therapeutic options for treatment of the multiresistant Acinetobacter baumannii infection, ${ }^{25}$ was not tested. Ahmed et al. that in Public Hospital in Alkharj, Acinetobacter baumannii bacteria were extensively drug resistant but its resistance was low to colistin. ${ }^{12}$ Dent $e t$ al. stated that $24772 \%$ of Acinetobacter baumannii isolates were multidrug resistant and that $58 \%$ of isolates were highly resistant to ampicillinsulbactam, amikacin, and imipenem. ${ }^{26}$ Eliopoulos et al. reported that among Acinetobacter isolates, an increasing antimicrobial resistance rate has been documented. ${ }^{27}$

Regarding gram positive bacteria, Enterococcus faecalis was highly resistant to erythromycin, tetracycline, and rifampin. Zaheer et al. found that the resistance rate of Enterococcus spp. to macrolides and tetracyclines was high. ${ }^{28}$ Kristich et al. reported that all enterococci show a reduced susceptibility to ampicillin and penicillin, along with high rate of resistance to semi-synthetic penicillins and cephalosporins. ${ }^{29}$ Jia et al. stated that a high prevalence of resistance to ampicillin, penicillin, rifampicin, levofloxacin, erythromycin, fosfomycin, furadantin, and ciprofloxacin was detected in Enterococcus species. ${ }^{30}$

Staphylococcus epidermidis was highly resistant to penicillin, ampicillin, oxacillin, azithromycin, and erythromycin. So these bacteria were multidrug resistant. Chabi and Momtaz found that Staphylococcus epidermidis strains harbored a high resistance rate against penicillin, erythromycin, tetracycline, trimethoprim-sulfamethoxazole, and cefazolin. ${ }^{31}$

\section{CONCLUSION}

This study provides essential data on antimicrobial resistance of bacterial isolates in a military hospital from $1^{\text {st }}$ of January 2021 to $30^{\text {th }}$ of June 2021. The study showed that Escherichia coli, Pseudomonas aeruginosa, Staphylococcus aureus, and Klebsiella pneumonia were common bacteria. The study also showed that Acinetobacter baumannii was a pandrug-resistant bacterium and Enterobacter cloacae, Proteus mirabilis, Morganella morganii, and Enterococcus faecalis bacteria were multidrug resistant. Consequently, Antibiotic susceptibility testing is an essential guide for physicians to help them in the selection of the suitable antibiotic for bacterial infections. 


\section{ACKNOWLEDGEMENT}

This Publication was supported by the Deanship of Scientific Research at Prince Sattam bin Abdulaziz University.

\section{REFERENCES}

1. CDC. Antibiotic use; 2021 [cited Sep 02 2021]. Available from: https://www.cdc. gov/antibiotic-use/index.html.

2. Alrasheedy AA, Alsalloum MA, Almuqbil FA, Almuzaini MA, Aba Alkhayl BS, Albishri AS, et al. The impact of law enforcement on dispensing antibiotics without prescription: A multi-methods study from Saudi Arabia. Expert Rev Anti-Infect Ther. 2020;18(1):87-97. doi: 10.1080/14787210.2020.1705156, PMID 31834825

3. Bell BG, Schellevis F, Stobberingh E, Goossens $H$, Pringle M. A systematic review and meta-analysis of the effects of antibiotic consumption on antibiotic resistance. BMC Infect Dis. 2014;14:13. doi: 10.1186/1471-2334-14-13, PMID 24405683

4. WHO. Antimicrobial resistance: global report on surveillance. Geneva; 2014 [cited Sep 02 2021]. Available from: https://www.who.int/drugresistance/ documents/surveillancereport/en/.

5. Yitayeh L, Gize A, Kassa M, Neway M, Afework A, Kibret M, et al. Antibiogram profiles of bacteria isolated from different body site infections among patients admitted to GAMBY Teaching General Hospital, Northwest, Ethiopia. Infect Drug Resist. 2021;14:2225-32. doi: 10.2147/IDR.S307267, PMID 34163187.

6. CDC. Antibiotic resistance threats in the United States; 2013 [cited Sep 02 2021]. Available from: http://www.cdc.gov/drugresistance/threat-report-2013/ pdf/arthreats-2013-508.pdf.

7. Maragakis LL, Perencevich EN, Cosgrove SE. Clinical and economic burden of antimicrobial resistance. Expert Rev Anti-Infect Ther. 2008:6(5):751-63. doi: 10.1586/14787210.6.5.751, PMID 18847410.

8. De Kraker ME, Wolkewitz M, Davey PG, Koller W, Berger J, Nagler J, et al. BURDEN Study Group. Clinical impact of antimicrobial resistance in European hospitals: Excess mortality and length of hospital stay related to methicillinresistant Staphylococcus aureus bloodstream infections. Antimicrob Agents Chemother. 2011;55(4):1598-605. doi: 10.1128/AAC.01157-10, PMID 21220533.

9. Cosgrove SE. The relationship between antimicrobial resistance and patient outcomes: Mortality, length of hospital stay, and health care costs. Clin Infect Dis. 2006;42; Suppl 2:S82-9. doi: 10.1086/499406, PMID 16355321.

10. Shih JD, Wood LSY, Dambkowski CL, Torres S, Chehab EF, Venook R, et al. An in vitro bacterial surface migration assay underneath sterile barrier material commonly found in a hospital setting. J Perinatol. 2017;37(7):848-52. doi: 10.1038/jp.2017.28, PMID 28333156

11. Schiavetti B, Wynendaele E, De Spiegeleer B. CIOMS Guide to vaccine safety communication. WHO Drug Inf. 2018;32:39-40

12. Ahmed $N J$, Haseeb $A$, Hassali MA, Elsaid EE, Khan AH. Antimicrobial resistance of ESKAPE pathogens in a public hospital in AlKharj. Lat Am J Pharm. 2021:40:442-50.

13. Ahmed NJ. Prevalence of bacterial pathogens isolated in 2018 from patients in a Military Hospital. J Int Pharm Res. 2020;32:35-9.

14. Ahmed NJ, Khan MF. Antibiotic resistance patterns in a university hospital in Al-Kharj city. JPRI. 2019;31:1-5. doi: 10.9734/jpri/2019/v31i530310.

15. Masoud EA, Mahdy ME, Esmat AM. Bacterial prevalence and resistance to antimicrobial agents in southwest, Saudi Arabia. Egypt Acad J Biol Sci. 2011;3:105-11.
16. Hamid ME, Mustafa FY, Alwaily A, Abdelrahman S, Al Azragi T. Prevalence of bacterial pathogens in Aseer region, Kingdom of Saudi Arabia: Emphasis on antimicrobial susceptibility of Staphylococcus aureus. Oman Med J. 2011;26(5):368-70. doi: 10.5001/omj.2011.91, PMID 22216389

17. Aly $\mathrm{M}$, Balkhy $\mathrm{HH}$. The prevalence of antimicrobial resistance in clinical isolates from Gulf Corporation Council countries. Antimicrob Resist Infect Control. 2012;1(1):26. doi: 10.1186/2047-2994-1-26, PMID 22958584.

18. Davin-Regli A, Pagès JM. Enterobacter aerogenes and Enterobacter cloacae; versatile bacterial pathogens confronting antibiotic treatment. Front Microbiol. 2015;6:392. doi: 10.3389/fmicb.2015.00392, PMID 26042091.

19. Malek A, McGlynn K, Taffner S, Fine L, Tesini B, Wang J, et al. Next-GenerationSequencing-Based Hospital Outbreak Investigation Yields Insight into Klebsiella aerogenes Population Structure and Determinants of Carbapenem Resistance and Pathogenicity. Antimicrob Agents Chemother. 2019;63(6):e02577-18. doi: 10.1128/AAC.02577-18, PMID 30910904

20. Wang JT, Chen PC, Chang SC, Shiau YR, Wang HY, Lai JF et al. TSAR Hospitals Antimicrobial susceptibilities of Proteus mirabilis: A longitudinal nationwide study from the Taiwan surveillance of antimicrobial resistance (TSAR) program. BMC Infect Dis. 2014;14:486. doi: 10.1186/1471-2334-14-486, PMID 25192738.

21. Tsai HY, Chen YH, Tang HJ, Huang CC, Liao CH, Chu FY, et al. Carbapenems and piperacillin/tazobactam for the treatment of bacteremia caused by extendedspectrum $\beta$-lactamase-producing Proteus mirabilis. Diagn Microbiol Infect Dis. 2014;80(3):222-6. doi: 10.1016/j.diagmicrobio.2014.07.006, PMID 25139843.

22. Magiorakos AP, Srinivasan A, Carey RB, Carmeli Y, Falagas ME, Giske CG, et al. Monnet DL. Multidrug-resistant, extensively drug-resistant and pandrugresistant bacteria: an international expert proposal for interim standard definitions for acquired resistance. Clin Microbiol Infect. 2012;18(3):268-81. doi: 10.1111/j.1469-0691.2011.03570.x, PMID 21793988.

23. Monnet D, Richard C. Autres Enterobacteriaceae. Manuel de bacteriologie Clinique. 1994; 1053-128.

24. Liu H, Zhu J, Hu Q, Rao X. Morganella morganii, a non-negligent opportunistic pathogen. Int J Infect Dis. 2016;50:10-7. doi: 10.1016/j.ijid.2016.07.006, PMID 27421818 .

25. Qureshi ZA, Hittle LE, O'Hara JA, Rivera JI, Syed A, Shields RK, et al. Colistinresistant Acinetobacter baumannii: Beyond carbapenem resistance. Clin Infect Dis. 2015:60(9):1295-303. doi: 10.1093/cid/civ048, PMID 25632010.

26. Dent LL, Marshall DR, Pratap S, Hulette RB. Multidrug resistant Acinetobacter baumannii: A descriptive study in a city hospital. BMC Infect Dis. 2010:10:196. doi: 10.1186/1471-2334-10-196, PMID 20609238

27. Maragakis LL, Perl TM. Acinetobacter baumannii: Epidemiology, antimicrobia resistance, and treatment options. Clin Infect Dis. 2008;46(8):1254-63. doi 10.1086/529198, PMID 18444865

28. Zaheer R, Cook SR, Barbieri R, Goji N, Cameron A, Petkau A et al Surveillance of Enterococcus spp. reveals distinct species and antimicrobial resistance diversity across a One-Health continuum. Sci Rep. 2020;10(1):3937. doi: 10.1038/s41598-020-61002-5. PMID 32127598.

29. Kristich CJ, Rice LB, Arias CA. Enterococcal infection-treatment and antibiotic resistance. Enterococci Commensals Leading Causes Drug Resistant Infect. 2014

30. Jia W, Li G, Wang W. Prevalence and antimicrobial resistance of Enterococcus species: A hospital-based study in China. Int J Environ Res Public Health 2014;11(3):3424-42. doi: 10.3390/ijerph110303424, PMID 24662964.

31. Chabi R, Momtaz H. Virulence factors and antibiotic resistance properties of the Staphylococcus epidermidis strains isolated from hospital infections in Ahvaz, Iran. Trop Med Health. 2019;47:56. doi: 10.1186/s41182-019-0180-7, PMID 31844416

Article History: Received: 02-09-2021; Revised: 29-09-2021; Accepted: 27-10-2021.

Cite this article: Ahmed NJ, Abdalla M, Alahmadi H, Haseeb A, Khan AH. Prevalence of Gram-negative and Gram-positive Bacteria and Antibiotic Resistance Rates at a Military Hospital in Riyadh Region. J Young Pharm. 2021;13(4):392-5. 